\title{
Analysis of Generalized Peukert's Equations for determining the capacity of nickel-cadmium batteries
}

\author{
Nataliya N. Yazvinskaya, Nikolay E. Galushkin", Dmitriy N. Galushkin.
}

Don State Technical University, Laboratory of electrochemical and hydrogen energy, 147 Shevchenko Street, Town of Shakhty, Rostov Region, Russia, 346500.

*E-mail: galushkinne@mail.ru

doi: $10.20964 / 2018.09 .61$

Received: 12 May 2018 / Accepted: 6 July 2018 / Published: 5 August 2018

In this paper, we analysed the use possibility of the generalized Peukert's equations $C=C_{m} /\left(1+\left(i / i_{0}\right)^{n}\right)$, $C=0.522 C_{m} \tanh \left(\left(i / i_{0}\right)^{n} / 0.522\right) /\left(i / i_{0}\right)^{\mathrm{n}}$, and $C=C_{m} \operatorname{erfc}\left(\left(i / i_{k}-1\right) / n\right) / \operatorname{erfc}(-1 / n)$ to compute the released capacity of nickel-cadmium batteries at different discharge currents. It was proven that these equations correspond well to the experimental data throughout the entire variation interval of discharge currents. It was shown that the parameter $n$ does not depend on the nominal capacity of the batteries under examination; however, it possesses various values for batteries of different modes of discharge (Long, Medium, High). Further, it was shown that the functional dependence of a battery's released capacity with a discharge current is determined by the statistical phase transition subjected to the normal distribution law. The proposed statistical mechanism allows us to explain the variation in parameter $n$ depending on the types of batteries under examination.

Keywords: Peukert's equation, modeling, battery, nickel-cadmium, capacity

\section{$\underline{\text { FULL TEXT }}$}

(C) 2018 The Authors. Published by ESG (www.electrochemsci.org). This article is an open access article distributed under the terms and conditions of the Creative Commons Attribution license (http://creativecommons.org/licenses/by/4.0/). 